\title{
Redação de resumo de tema livre para congresso médico
}

\author{
Sebastião Silva Gusmão*, Roberto Leal Silveira* \\ RESUMO \\ Descrevem-se as orientações básicas para redação do Resumo de trabalho científico a ser \\ submetido a congresso médico, por meio da análise das diferentes partes ou seções desse tipo \\ de trabalho. \\ PALAVRAS-CHAVE \\ Artigo científico. Resumo. Redação. \\ ABSTRACT \\ Writing the summary of papers for presentation in scientific meetings \\ It is presented a basic orientation for the writing of the summary of scientific papers for medical \\ congress through analysis of their component parts.

\section{KEYWORDS} \\ Scientific paper. Summary.
}

A sessão de tema livre em congressos é uma das formas mais efetivas de se comunicar resultados de pesquisas em Medicina. O tema livre é encaminhado à organização do congresso sob a forma de resumo.

Resumo é a apresentação sintética dos pontos relevantes de um trabalho, devendo refletir os dados fundamentais da investigação. É um artigo em miniatura que tem por objetivo fornecer uma visão panorâmica do conteúdo do trabalho. Para cumprir esse objetivo, deve mostrar o que foi feito, por que foi feito, como foi feito, o que foi encontrado e quais as implicações. O Resumo bem elaborado é preciso e completo e, ao mesmo tempo, conciso.

Em 1987 o Ad Hoc Working Group for Critical Appraisal of the Medical Literature ${ }^{1}$ propôs o resumo estruturado para trabalho original, segundo o plano IMRED ${ }^{2}$, ou seja:

- Introdução (apresenta o problema a ser estudado);

- Material e métodos (como o problema foi estudado);

- Resultados (qual a resposta encontrada);

- Discussão (o que significa essa resposta).

Além dessas partes, o Resumo de trabalho científico tipo do original contém elementos complementares.
Antes da Introdução, expõem-se o título do trabalho, acompanhado de nome, credenciais e local de atividade do autor ou autores.

A composição completa do Resumo de trabalho original, do tipo experimental, é, portanto, constituída pelas seguintes partes: título do trabalho, nome do(s) autor(es), credenciais do(s) autor(es), local de atividade do(s) autor(es), Introdução, Material e métodos, Resultados e Discussão ${ }^{4}$.

No Resumo de trabalho do tipo relato de caso, as seções Material e método e Resultados são substituídas pela seção Relato de caso ${ }^{4}$.

O resumo de comunicação de tema livre para congresso é um resumo informativo, próximo daquele de um artigo experimental ou relato de caso, apresentando algumas particularidades. É recomendável privilegiar a exposição dos Resultados em detrimento à Discussão. Esta seção se restringe, ou melhor, é substituída pela apresentação das Conclusões ${ }^{5}$.

Da mesma forma que a observação clínica e o trabalho experimental têm de obedecer a preceitos de técnica e de método, a redação de trabalho científico não pode fugir a certas normas fundamentadas na lógica, na coerência e na gramática. Nosso objetivo é

* Faculdade de Medicina da Universidade Federal de Minas Gerais. Serviço de Neurocirurgia do Hospital Madre Teresa. Serviço de Neurocirurgia do Hospital Luxemburgo. 
expor as normas básicas de redação de resumo de tema livre a ser apresentado em congresso. Analisaremos a redação das diferentes partes ou seções desse tipo de texto.

\section{Seções do resumo}

\section{Título}

O Título é o rótulo que indica o conteúdo do trabalho. Deve expressar, de forma clara e no menor número de palavras, o conteúdo do trabalho. É aconselhável elaborá-lo a partir das palavras-chave, ou seja, os termos determinantes para se caracterizar o trabalho.

\section{Introdução}

O Resumo deve iniciar-se por uma ou duas frases que sumarizam a razão de se realizar o trabalho. É fundamental que o leitor compreenda por que o trabalho foi feito.

A seguir, apresenta-se o objetivo. Ele deve expressar qual questão específica se deseja responder. Muitas vezes tal objetivo é omitido por já estar expresso no Título. A frase inicial do resumo não deve repetir o que está dito no Título.

Recomenda-se entrar diretamente no assunto, evitando as expressões:

$\mathrm{O}$ autor descreve..., $\mathrm{O}$ autor encontrou..., $\mathrm{O}$ autor pesquisou... Neste trabalho, o autor expõe..., Os resultados da pesquisa são apresentados...

São expressões desnecessárias, pois, se alguém descreveu, encontrou, pesquisou ou expôs alguma coisa no trabalho, é óbvio que foi o autor. Por isso, usa-se: descreve-se, encontrou-se, pesquisou-se, expõe-se.

A formulação do objetivo da investigação, isto é, a hipótese a ser confirmada ou não, que se pretende alcançar ou testar, deve ser expressa de forma precisa e clara. $\mathrm{Na}$ sua redação, usa-se a forma infinitiva dos verbos.

\section{Material e métodos}

Descreve em linguagem precisa e técnica como o estudo foi desenvolvido. Em Material (ou Casuística), descreve-se a seleção feita dos sujeitos observados ou que participam da experiência (pacientes, animais). Em Métodos, relatam-se os procedimentos que operacionalizam a pesquisa proposta.

\section{Resultados}

É a parte fundamental do Resumo. Nela são enumerados de forma simples e precisa os resultados principais da execução do método para cumprir os objetivos, indicando os valores mais representativos, com significação estatística.

\section{Relato do caso}

O caso é relatado de forma objetiva e concisa, enfocando os aspectos essenciais que caracterizam a doença. Expõem-se, em parágrafos sucessivos, a história, o exame físico, os exames complementares, a evolução, os resultados e, se houver, o exame necroscópico. Pode-se descrever um paciente, uma família ou uma pequena amostra de pacientes.

$\mathrm{Na}$ descrição do caso, o verbo é usado no passado. Os dados negativos da história e do exame físico são incluídos apenas quando importantes para a compreensão do caso. Quanto às datas, os eventos são referidos no início da doença ou no momento da internação ou da intervenção cirúrgica. Ao longo da narração, as demais ocorrências são referidas em relação ao evento escolhido como referência.

\section{Conclusão}

Deve-se estabelecer de forma clara e precisa a conclusão sobre o significado do trabalho. É redigida no presente. Com base na interpretação dos resultados, admite-se fazer recomendações, sugerir possíveis aplicações, apontar novas relações ou sugerir outras pesquisas. Somente são apropriadas as conclusões fundamentadas nos resultados da pesquisa, não cabendo quaisquer conclusões a que se tenha chegado pelo estudo da literatura ou pela experiência pessoal do autor.

\section{Apresentação do resumo}

Quanto à apresentação, o Resumo de tema livre deve formar um todo, podendo, assim, ser publicado independentemente nos anais do congresso. Terá número limitado de palavras, geralmente em torno de 200 palavras ou 15 linhas, e será redigido em linguagem simples, clara, concisa e precisa, com frases curtas e completas. Para o controle da extensão do texto, usa-se o processador de texto para a contagem automática do número de caracteres, de palavras e de linhas ${ }^{3,7}$. 
Para fins de indexação, o Resumo deve incluir termos representativos e palavras-chave relacionadas ao assunto. Os verbos são colocados no passado, quando se referem ao trabalho apresentado, recomendando-se o uso da terceira pessoa do singular. A conclusão é redigida no presente. $\mathrm{O}$ texto deve ser composto em seqüência corrente de frases concisas, e não de enumeração de tópicos ${ }^{3}$.

As abreviaturas devem ser evitadas, a não ser quando um termo se repete várias vezes. Nesse caso, a abreviatura será dada entre parênteses em sua primeira menção e será utilizada a seguir. A Referência bibliográfica só é citada eventualmente, quando se menciona uma modificação de método.

A redação de um Resumo eficiente e competitivo é fundamental para submeter-se um trabalho às sessões de temas livres dos congressos médicos. A seleção basear-se-á no conteúdo (rigor científico e importância da mensagem) e na forma (linguagem e expressão). Afinal, o autor do trabalho será julgado pelo texto que apresentar. Um bom trabalho de pesquisa pode não ser selecionado em congresso médico, ou ser subvalorizado, por causa da apresentação precária. Como se escreve (a forma) é, no mínimo, tão importante como o que se escreve (o conteúdo) . $^{5}$.

Três qualidades principais contribuem para $\mathrm{o}$ sucesso da seleção do Resumo em um congresso: conteúdo, apresentação e observância das normas estabelecidas pela direção do congresso ${ }^{5}$.

O conteúdo deve trazer informações específicas, capazes de evidenciar que o trabalho não só foi bem planejado, como foi executado com rigor.

Resumos com boa apresentação provocam impressão inicial favorável. Erros de grafia, incorreção gramatical e outros defeitos causam má impressão e sugerem baixa qualidade da pesquisa propriamente dita. Isso pode levar à supervalorização da apresentação em detrimento ao conteúdo, o que é lamentável. De qualquer modo, não se pode esquecer que o trabalho bem planejado e executado pode não ter sucesso se a apresentação for descuidada.

Quanto à apresentação do texto, o Resumo deve ter as qualidades essenciais do texto científico: clareza, concisão e precisão ${ }^{3,6,7}$.

Clareza consiste na expressão límpida do pensamento, na transparência ou na nitidez que torna o texto facilmente compreensível. Para atingir a linguagem clara, use frases curtas e na ordem direta e opte pela palavra mais simples que defina a coisa ou situação referida.

Concisão é o emprego do menor número possível de palavras para exprimir o pensamento. Para alcançar concisão deve-se excluir pormenores insignificantes e características irrelevantes e eliminar palavras e adjetivos inúteis.
Precisão ou propriedade é o ajustamento da palavra ao significado e da frase ao pensamento. Cada termo, cada expressão e cada tempo de verbo deve ser escolhido, cuidadosamente, para que signifique, exatamente, o que o autor quer dizer. Das palavras, no artigo científico, exige-se quase a mesma precisão dos símbolos em uma equação matemática.

Para conseguir clareza, concisão e precisão, é necessário rever o texto várias vezes para corrigi-lo e cortar o supérfluo. Deve-se procurar a formulação mais simples, com economia de palavras.

Para a confecção de resumos de temas livres em congresso há normas prévias sobre a redação e a diagramação para facilitar a publicação no livro de temas livres ou nos anais do congresso. O Resumo deverá estar contido nos limites do formulário-padrão adotado pelos organizadores do congresso. Deve-se seguir as normas de impressão recomendadas: tipo e tamanho de fonte, tamanho do espaçamento entre as linhas, tipo de editor de texto (geralmente uma versão atualizada do Winword) e outras recomendações quanto a apresentação do título, nome e número de autores, endereço do autor principal e instituição onde o trabalho foi realizado. Geralmente solicita-se enviar o original do Resumo em disquete e algumas cópias. É essencial a observância dessas normas, pois os resumos encaminhados são geralmente publicados sem editoração adicional, ou seja, exatamente na forma que foram encaminhados.

\section{Exemplo de resumo}

Hematoma extradural e lesão axonal difusa em vítimas fatais de acidente de trânsito

\section{Introdução}

O objetivo do presente trabalho é estudar, do ponto de vista clínico (estado de consciência) e anatomopatológico, a associação de hematoma extradural (HED) e lesão axonal difusa (LAD) em vítimas fatais de acidente de trânsito.

\section{Casuística e método}

Foram estudadas 120 vítimas fatais de acidente de trânsito submetidas a exame anatomopatológico macroscópico e microscópico pelo método de GleesMarsland para identificação de axônios. O estado de consciência à admissão hospitalar foi avaliado pela escala de coma de Glasgow. 


\section{Resultados}

O hematoma extradural foi observado em 7 pacientes $(5,8 \%)$, sendo todos do sexo masculino e com idade entre 18 e 64 anos. A sobrevida variou de 1 a 16 dias. Todos foram internados em estado de coma (escala de coma de Glasgow de 3 a 8) e apresentaram LAD.

\section{Conclusão}

O HED é relativamente pouco freqüente no acidente de trânsito, mas, nesses casos, são mais graves pela associação com LAD. Essa lesão explica o coma imediato (ausência de intervalo livre) e o mal prognóstico desses pacientes.

\section{Referências}

1. AD HOC WORKING GROUP FOR CRITICAL APPRAISAL OF THE MEDICAL LITERATURE: A proposal for more informative abstracts of clinical articles. Ann Intern Med 106:598-604, 1987.

2. COMROE JH: Tell it like it was. Retrospective: Insights into medical discovery. Menlo Park, CA, von Gehr Press, 1977.

3. DAY RA: How to write and publish a scientific paper. Ed 5. Phoenix, Oryx Press, 1998.

4. INTERNATIONAL COMMITTEE OF MEDICAL JOURNAL EDITORS: Uniform requirements for manuscripts submitted to biomedical journals. $\mathrm{N}$ Engl J Med 336:309-15, 1997.

5. PANUSH RS, DELAFUENTE JC, CONNELLY CS, EDWARDS NL, GREER JM, LONGLEY $S$ et al.: Profile of a meeting: how abstracts are written and reviewed. J Rheumatol 16:145-7, 1989.

6. RAMÓN Y CAJAL S: Reglas y consejos sobre investigatión científica. Madrid, Aguilar, 1961.

7. WHITE EB, STRUNK W: The elements of style. New York, MacMillian, 1972

Original recebido em dezembro de 2000

Aceito para publicação em março de 2001

\section{Endereço para correspondência:}

Rua Padre Rolim, 921/21

CEP 30130-090 - Belo Horizonte, $M G$

E-mail:gusmao@medicina.ufmg.br 